MSC 90C35, 90C27

DOI: $10.14529 / \operatorname{mmp} 180107$

\title{
ALGORITHM OF EFFECTIVE TRANSPORTATION WORK FOR CARGO TRAFFIC
}

\author{
M.V. Buyanov, A.I. Kibzun \\ Moscow Aviation Institute, Moscow, Russian Federation \\ E-mail: buyanovmikhailv@gmail.com, kibzun@mail.ru
}

\begin{abstract}
We suggest a mathematical model that describes railway network. This model is applied to the problem of allocation locomotive for transportation of freight trains. The aim of the optimization is to minimize the size of active locomotive fleet by choosing trains and locomotives routes. An alternative formulation of the optimization problem is proposed with the usage of a heuristic objective function, which makes it possible to construct an effective decision algorithm. A new deterministic algorithm for suboptimal control is described. This algorithm is a modification of the previously proposed, based on the construction of routes tree for each locomotive and, subsequently, the choice of such a route, in which the maximum value of the given objective function is reached. Numerical experiments were carried out on the example of the historical data of the Moscow Railway. The analysis and comparison of the results are given.
\end{abstract}

Keywords: graph theory; integer optimization; allocation of locomotives.

\section{Introduction}

Recently, the strategy of scientific and technological research of the Russian Railways is especially aimed at carrying out complex works on the improvement and automation of cargo management systems.

In many works [1-8] various methods and algorithms for the optimization of cargo transportation by railway transport are considered. In [4] means for improving the organization of freight transport are proposed. These means are based on the consideration of a single model of the logistics supply chain of goods, including the production, construction, reconstruction and maintenance of infrastructure, ensuring the reception of all trains without delay, taking into account the uneven movement. The deterministic combinatorial problem of forming trains and planning schedules for rail transport is formulated in $[6,7]$. In [7] various models are presented, which arise during planning the movement in railway transport, in particular, the model of the operational control of the movement of the composition and the model of the formation of freight flows through the sorting stations. In [8] two combinatorial problems are considered: the problem of scheduling a non-periodic schedule and the problem of assigning a train to the platform.

\section{Main Definitions}

Let a directed graph $G=(V, A)$ corresponds to a part of a railway, where $V$ is a set of vertices, $A$ is a set of edges. The vertices of the graph $G$ are the main stations (freight distribution center and stations where locomotives are changed). The edges of the graph 
$G$ are the ways connecting the main stations. Some main stations are also depots. Let us denote the corresponding subset of $V$ by $D$.

Locomotives may move only by defined routes (so-called railway hauls), so we introduce the following definition.

Definition 1. A sequence of edges $a_{1}, \ldots, a_{I_{P}}$ of the graph $G$ is a railway haul $P$ if the following conditions hold:

1. Each edge $a_{i}=\left(v_{i-1}, v_{i}\right)$ is distinguished from other edges: $a_{i} \neq a_{j}, i, j \in\left\{1, \ldots, I_{P}\right\}$.

2. The first vertex of first edge coincides with the last vertex of last edge, is a depot, and differs from other vertices in the sequence: $v_{1}=v_{P} \in D, v_{i} \neq v_{1}$ for $i=\overline{2, I_{P}-1}$.

Also, we will consider subhauls and simple subhauls.

Definition 2. Any subsequence of adjacent edges $a_{i}, a_{i+1}, \ldots, a_{j}\left(1 \leq i<j \leq I_{P}\right)$ belonging to the haul $P$ is a subhaul of the haul. Any edge $a_{i}=\left(v_{i-1}, v_{i}\right)$ belonging to the haul $P$ is called a simple subhaul.

Let $L$ be the set of all considered locomotives. For any locomotive $l \in L$, a set of feasible railway hauls is determined.

Let us define the set $\mathcal{P}_{l}$ for any set $\overline{\mathcal{P}}_{l}, l \in L$. The set $\mathcal{P}_{l}$ contains all simple subhauls of hauls of the set $\overline{\mathcal{P}}_{l}$.

Let $S$ be a set of carried freight trains. Each train is described by its dispatch station $v_{0}^{s}$, receiving station $v_{f}^{s}$, readiness time $t_{0}^{s}$, time $\tau_{f}^{s}$, until which the train has to arrive at the receiving station. This means that the tuple $\left(v_{0}^{s}, t_{0}^{s}, v_{f}^{s}, \tau_{f}^{s}\right)$ corresponds to the train $s$. Notice that this tuple defines the plan of transportation.

Locomotives and trains can move by preassigned routes only in certain periods of time called train paths.

Definition 3. A sequence of tuples $\left(v_{1}, t_{1}, v_{2}, \tau_{2}\right), \quad\left(v_{2}, t_{2}, v_{3}, \tau_{3}\right), \quad \ldots$, $\left(v_{I_{N}-1}, t_{I_{N}-1}, v_{I_{N}}, \tau_{I_{N}}\right)$, is said to be a path $N$ if the following conditions hold:

1) $v_{i} \in V, i=\overline{1, I_{N}}, t_{i} \in \mathbb{R}, i=\overline{1, I_{N}-1}, \tau_{i} \in \mathbb{R}, i=\overline{2, I_{N}}$;

2) $\left(v_{i}, v_{i+1}\right) \in A, i=\overline{1, I_{N}-1}$;

3) $t_{i}<\tau_{i+1}, i=\overline{1, I_{N}-1}$;

4) $\tau_{i} \leq t_{i}, i=\overline{2, I_{N}}$.

In this definition, $t_{i}$ corresponds to the departure time from the station $v_{i}, \tau_{i+1}$ corresponds to the arrival time to the station $v_{i+1}$. The introduced conditions show restrictions related with the movement of locomotives. Conditions 1 and 2 require that the locomotives can move only by edges, condition 3 means that the departure time from the current station is earlier than the arrival time to the next station, condition 4 means that the arrival time to the station is earlier than the departure time from this station.

By analogy with subhauls and simple subhauls, let us introduce subpaths and simple subpaths.

Definition 4. Any subsequence of adjacent tuples belonging the train path $N$ is called a subpath. Any tuple $\left(v_{i}, t_{i}, v_{i+1}, \tau_{i+1}\right), i=\overline{1, N-1}$, belonging to the train path $N$ is called a simple subpath. 
Let a set $\overline{\mathcal{N}}$ of train paths be given. Let the unordered set of all simple subpaths belonging to each path $N \in \overline{\mathcal{N}}$ denote by $\mathcal{F}(N)$. We denote the set of all simple subpath belonging to the set $\overline{\mathcal{N}}$ by $\mathcal{N}$, i.e.

$$
\mathcal{N}=\bigcup_{N \in \overline{\mathcal{N}}} \mathcal{F}(N)
$$

Since the locomotives move only by paths and hauls, we introduce the definition of a feasible route with respect to the set of hauls. In this definition, we take into account that the locomotives have to undergo maintenance not later than in time $T$ (48 hours) after the previous maintenance. The duration of maintenance is denoted by $t_{T O}$ ( 8 hours). It is assumed that at the initial time each locomotive $l \in L$ is described by time interval $\tau_{T O}^{l}$, which has passed since the previous maintenance. If a locomotive undergoes maintenance at the initial time then the value $\tau_{T O}^{l}$ is negative and equals in magnitude the time remaining until the finish of the maintenance.

Definition 5. A subsequence of simple subpaths $\left(v_{1}, t_{1}, v_{2}, \tau_{2}\right),\left(v_{2}, t_{2}, v_{3}, \tau_{3}\right), \ldots$, $\left(v_{I_{l}-1}, t_{I_{l}-1}, v_{I_{l}}, \tau_{I_{l}}\right)$ is called a feasible route $M_{l}$ of the locomotive $l$ with respect to the set of hauls $\overline{\mathcal{P}}_{l}$ if the following conditions hold:

1) $\tau_{i} \leq t_{i}, i=\overline{2, I_{l}-1}$;

2) $\left(v_{i}, v_{i+1}\right) \in \mathcal{P}_{l}, i=\overline{1, I_{l}-1}$;

3) there exists an increasing subsequence $i_{1}, \ldots, i_{f_{l}}$ of numbers from the set $\left\{2,3, \ldots, I_{l}\right\}$ such that

$$
\begin{gathered}
\tau_{T O}^{l}+\tau_{i_{1}} \leq T, \\
t_{i_{j}}-\tau_{i_{j}} \geq t_{T O}, \quad j=\overline{1, f_{l}-1}, \\
\tau_{i_{j}}-t_{i_{j-1}} \leq T, \quad j=\overline{2, f_{l}}, \\
\tau_{I_{l}}-t_{f_{l}} \leq T, \text { if } f_{l} \neq I_{l} .
\end{gathered}
$$

Condition 1 requires that the arrival time to the station is earlier than the departure time from this station. Condition 2 restricts a feasible transportation by the hauls. Condition 3 requires maintenances in certain time interval. The sequence $t_{i_{1}}, \ldots, t_{i_{f_{l}}}$ corresponds to the times of the maintenances start. According to (1) the time of the first maintenance the start is not later than time interval $T$ since the previous maintenance. According to (2) the maintenance cannot be less than $t_{T O}$. It follows from (3) that time interval between the departure after the maintenance and the next maintenance cannot be more than $T$. According to (4), the departure time after the last maintenance must be later than the time $T$ before the arrival to the route termination.

Note that the route is a spatiotemporal concept. Let us denote the set of feasible routes of the locomotive $l$ by $\mathcal{M}_{l}$. The initial and terminal stations of the route $M_{l}$ are denoted by $v_{0}\left(M_{l}\right)$ and $v_{f}\left(M_{l}\right)$ respectively. The time of the first path beginning in the route is denoted by $t_{0}\left(M_{l}\right)$. The arrival time to the terminal station is denoted by $\tau_{f}\left(M_{l}\right)$.

Let us introduce the definition of a train feasible route. This concept is also spatiotemporal.

Definition 6. A sequence of simple subpaths $\left(v_{1}, t_{1}, v_{2}, \tau_{2}\right), \quad\left(v_{2}, t_{2}, v_{3}, \tau_{3}\right), \ldots$, $\left(v_{I_{s}-1}, t_{I_{s}-1}, v_{I_{s}}, \tau_{I_{s}}\right)$ is called a feasible route of the train $s \in S$ and is denoted by $R_{s}$ if the following conditions hold: 
1) $v_{1}=v_{0}^{s}$

2) $v_{I_{s}}=v_{f}^{s}$

3) $\tau_{i} \leq t_{i}, i=\overline{2, I_{s}-1}$;

4) $t_{0}^{s} \leq t_{1}$

5) $\tau_{f}^{s} \geq \tau_{I_{s}}$.

Conditions 1 and 2 define the initial and terminal stations of the route, condition 3 restricts the departure and arrival time, conditions 4 and 5 require to carry out all needed transportation on time.

The set of feasible routes of the train $s$ is denoted by $\mathcal{R}_{s}$.

Let us define the set $\mathcal{F}\left(M_{l}\right)$ of all simple subpaths belonging to the route $M_{l}$ for all locomotives $l, l \in L$. Also, we define the set $\mathcal{F}\left(R_{s}\right), s \in S$, of all simple subpaths belonging to the route $R_{s}$ of the train $s$.

\section{Statement}

Let us consider the part of the railway, which corresponds to the graph $G=(V, A)$ defined above. Suppose that $L$ is a set of locomotives, $S$ is a set of trains, $\overline{\mathcal{N}}$ is a set of paths. Let $\mathcal{N}$ be the corresponding set of simple subpaths. For all locomotives $l \in L$, a set $\overline{\mathcal{P}}_{l}$ of hauls is defined. Let $\mathcal{P}_{l}$ be the set of simple subhauls.

At the initial time, some locomotives can move, so it is supposed that locomotive $l \in L$ can depart only from the fixed station $v_{0}^{l}$ after the time $t_{0}^{l}$.

Let the time $\tau_{T O}^{l}$ since the previous maintenance is given for all locomotives $l \in L$. The set of feasible routes $\mathcal{M}_{l}$ is given according to definition 5 taking into account the time $\tau_{T O}^{l}$ for all locomotives $l \in L$. Similarly, for all trains $s \in S$, the set of feasible routes $\mathcal{R}_{s}$ is given. Let $|L|$ be the number of locomotives from the set $L$ with non-empty route.

Let the set of paths $\overline{\mathcal{N}_{s}} \subset \overline{\mathcal{N}}$ that can be used to carry the train be given for all trains $s \in S$. The set of all corresponding simple subpaths is denoted by $\mathcal{N}_{s}$. These constraints are needed because some paths can be used only for certain transportation.

Let $M=\left\{M_{l}\right\}_{l \in L}$ be a selected set of routes for all locomotives, $R=\left\{R_{s}\right\}_{s \in S}$ be a selected set of routes for all trains, $\mathcal{M}=\left\{\mathcal{M}_{l}\right\}_{l \in L}$ be a set of feasible routes for all locomotives, $\mathcal{R}=\left\{\mathcal{R}_{s}\right\}_{s \in S}$ be a set of feasible routes for all trains.

It is required to select a set $M$ of the locomotive routes and a set $R$ of the train routes such that the number $|L|$ of the exploited locomotives is minimal and all train routes are covered by locomotive routes. This means that the following problem should be solved:

$$
|L| \rightarrow \min _{M \in \mathcal{M}, R \in \mathcal{R}}
$$

subject to

$$
\begin{gathered}
M_{l} \in \mathcal{M}_{l}, l \in L, \\
R_{s} \in \mathcal{R}_{s}, s \in S, \\
\bigcup_{s \in S} \mathcal{F}\left(R_{s}\right) \subset \bigcup_{l \in L} \mathcal{F}\left(M_{l}\right), \\
\mathcal{F}\left(R_{s}\right) \cap \mathcal{F}\left(R_{s^{\prime}}\right)=\varnothing, s \neq s^{\prime}, s, s^{\prime} \in S, \\
\mathcal{F}\left(M_{l}\right) \subset \mathcal{N}, l \in L,
\end{gathered}
$$




$$
\begin{gathered}
\mathcal{F}\left(R_{s}\right) \subset \mathcal{N}_{s}, s \in S, \\
v_{0}\left(M_{l}\right)=v_{0}^{l}, \\
t_{0}\left(M_{l}\right) \geqslant t_{0}^{l} .
\end{gathered}
$$

Conditions (6) and (7) mean that we consider only the feasible locomotive routes and train routes. In particular, this means that feasible hauls exist for feasible routes. Also, notice that the feasible route requires to carry out the plan on time.

Condition (10) requires that the train routes contain only simple subpaths, because the set $\bigcup_{l \in L} \mathcal{F}\left(M_{l}\right) \subset \mathcal{N}$ contains simple subpaths that belong to some route of locomotive. Condition (11) defines the similar requirement for train routes, moreover, it restricts the selection of feasible paths to carry a train. Condition (8) means that all simple subpaths belonging to the route of a train are used for a locomotive, i.e. all trains are carried by the locomotives. Also, it follows from this condition that the locomotives can move by simple subpaths that are not used by trains. Therefore, each used path corresponds to a train with one or several locomotives or to a locomotive without train.

Condition (9) means that the routes of trains cannot intersect, i.e., one simple subpaths cannot be used for two trains. Since the locomotives can move together or with a train (so-called auxiliary run), the similar condition is not used for the locomotives.

Conditions (12) and (13) define an initial state of the locomotives.

Notice that the set $S$ of trains and the set $\overline{\mathcal{N}}$ of paths are defined by the daily transportation plan and by the number of days of the general plan.

In the formulated problem, routes of the locomotives and trains should be selected. Let us consider a special case of the problem (5) - (13), by refusing optimization on trains and solving only the task of locomotives allocation. So, we suppose below that the set of feasible routes $\mathcal{R}_{s}$ of the train $s \in S$ contains only one route. Therefore, the problem is reduced to the problem of locomotive allocation to carry trains with certain routes.

Let us write the objective function that helps us to make decision about the rote $M_{l}$ from the set of feasible traffic routes $\mathcal{M}_{l}$ :

$$
\Phi\left(M_{l}\right)=\left|M_{l}\right|
$$

Thus, we can formulate an optimization problem of choosing the optimal route for the locomotive in the sense of the objective function (14):

$$
\Phi\left(M_{l}\right) \rightarrow \max _{M_{l} \in \mathcal{M}_{l}}
$$

subject to $(6)-(13)$.

Solving the formulated problem by specifying the optimal routes for the sequence of locomotives allows us to find a suboptimal solution of the problem of the optimal assignment of locomotives (5) - (13) formulated in [1]. Algorithm for this suboptimal solutions is described in the following section.

\section{Algorithm of Locomotives Allocation}

Let a non-empty set $S=\left\{s_{i} \mid i=\overline{1,|S|}\right\}$ of trains with non-empty routes be given. Let $n=\left(\cdot, \cdot, v_{f}^{l}, \tau^{l}\right)$ be the terminal simple subpath of the route $M_{l}, v_{f}^{l}$ be the terminal station 
of the route (or initial station in case of an empty route) and $\tau^{l}$ be the arrival time of the locomotive $l \in L$ at the station $v_{f}^{l}$. The algorithm is based on building of the possible routes tree for the locomotive and further selecting the desired route depending on the given criterial function $\Phi$. We denote routes tree of the locomotive $l$ by $T_{l}$, the vertices in the tree are simple subpaths, the root of the tree $\mathrm{f}$ is a simple sbpath $n$.

\section{Algorithm}

0 . Let $i:=1, j:=1, k:=1, m:=1$.

1. For the locomotive $l_{i} \in L$, we put simple subpath $n$ to the root of the tree $T_{l}$.

2. State train $s_{j} \in S$, and simple subpath $n_{k} \in R_{s_{j}}$.

3. If $\tau^{l_{i}} \leqslant t\left(n_{k}\right),\left(v_{0}\left(n_{k}\right), v_{f}\left(n_{k}\right)\right) \in \mathcal{P}_{l_{k}}$, proceed to step 4, otherwise go to 5 .

4. If $v_{f}^{l_{i}} \neq v_{0}\left(n_{k}\right)$, then search a simple subpath $N^{*}$ for distillation of a locomotive $l_{i}$ to $n_{k}$, if it is not found, then make $j:=j+1, k:=0$ and go back to 3. Proceed to step 5 .

5. If $j=|S|$ and $k=\left|\mathcal{F}\left(R_{s}\right)\right|$, then procced to 7 , otherwise let $j:=j+1, k:=0$ and go back to step 3 .

6. Put simple subpath $n_{k}$ in the tree $T_{l}$ on level $m$.

7. We will consider each resulting leaf as the route of a new tree, if $m=m^{*}$ go to step 8 , otherwise we accept $m:=m+1$, for each resulting tree, we repeat the algorithm steps from the second one.

8. The tree is built. According to the given criterial function $\Phi$, we select the best route from the resulting tree. If there are not transported trains, set $i:=i+1$, go to step 1 , otherwise, go to step 9.

9. The end of the algorithm, the solution of the problem is obtained.

The algorithm allows us to find a suboptimal solution of the problem of assigning locomotives to compositions in the sense of a given criterial function $\Phi$. The variable $m^{*}$ used in step 7 of the algorithm limits the depth of the tree construction. The algorithm has a recursive structure. Note also that the described algorithm is labour-intensive (it is not difficult to prove its exponential complexity). Nevertheless, for daily planning and in conditions of a small number of permissible train paths for each locomotive, the usage of such an algorithm proves to be effective.

\section{Numerical Experiment Results}

Numerical experiment was executed with the help of data provided by Moscow Railway. Initial data characteristics are presented in Table 1.

Table 1

Initial data

\begin{tabular}{|l|l|}
\hline The number of stations & 40 \\
\hline The number of depot-stations & 16 \\
\hline The number of marshalling yards & 16 \\
\hline The number of trains in daily movement plan & 598 \\
\hline The number of paths per day & 1254 \\
\hline Plan period (days) & 5 \\
\hline
\end{tabular}


Here is Table 2 "Locomotives usage" for the solution obtained using the algorithm described in the previous section. There are 6 rows in Table 2 because the first and the last days are not complete (12 hour period was considered).

Table 2

Locomotives usage

\begin{tabular}{|c|c|l|l|l|l|l|l|l|}
\hline $\begin{array}{c}\text { Number of } \\
\text { trains }\end{array}$ & Day & \multicolumn{6}{l|}{$\begin{array}{l}\text { Number of locomotives exploited during the } i \text {-th day } \\
\text { and taken in the } j \text {-th day }\end{array}$} & Total \\
\hline & & 1 & 2 & 3 & 4 & 5 & 6 & \\
\hline 299 & 1 & 321 & 0 & 0 & 0 & 0 & 0 & 321 \\
\hline 598 & 2 & 319 & 79 & 0 & 0 & 0 & 0 & 408 \\
\hline 598 & 3 & 320 & 74 & 3 & 0 & 0 & 0 & 407 \\
\hline 598 & 4 & 321 & 78 & 2 & 1 & 0 & 0 & 420 \\
\hline 598 & 5 & 320 & 79 & 3 & 1 & 0 & 0 & 416 \\
\hline 299 & 6 & 294 & 50 & 1 & 1 & 0 & 0 & 350 \\
\hline
\end{tabular}

It is not difficult to see that the matrix track is the value of the objective function. Let us mention that new locomotives are not being put into operation at the end of the period. This indicates the stabilization process. To compare with [1] we got two times faster stabilization and the same locomotive fleet size.

Let us compare the solution with the historical data of locomotives usage by Moscow Railway. Overall locomotive Moscow Railway fleet is about 900 locomotives. 700 of them are used every day. Thus, we can make a conclusion that our solution is two times better than the current one. However, it should be noted that the model does not take into account all limitations in the real work of the railway.

\section{Conclusion}

In this work, the mathematical model to allocate locomotives for transportation of freight trains is suggested, the algorithm to solve the problem and its software implementation are developed.

A mathematical model of the designation of locomotives for the transportation of freight trains is proposed in the paper. An alternative formulation of the optimization problem is presented with the use of a heuristic objective function. An effective algorithm for solving the problem was developed and its software implementation was carried out. The result of numerical experiments has shown that the suggested method allows us to reduce the number of exploited locomotives about twice. However, we should notice that in practice this result is difficult to obtain, because in the considered example a lot of constrains are not taken into account, particularly, we consider only one type of maintenance, we do not consider possible random deviations from the timetable. But the obtained result allows us to hope that the found solution will provide effective locomotives usage. 
Acknowledgement. The first author's work was supported by Ministry of Education and Science of the Russian Federation (project 2.2461.2017/PCh) The second author's work was supported by the Russian Fondation for Basic Research and JSCo "RZD" (project 17-20-03050 ofi_m_RZD).

\title{
References
}

1. Azanov V.M., Buyanov M.V., Gaynanov D.N., Ivanov S.V. Algorithm and Software Development to Allocate Locomotives for Transportation of Freight Trains. Bulletin of the South Ural State University. Series: Mathematical Modelling, Programming and Computer Software, 2016, vol. 9, no 4, pp. 73-85. DOI: 10.14529/mmp160407

2. Buyanov M.V., Ivanov S.V., Kibzun A.I., Naumov A.V. Development of the Mathematical Model of Cargo Transportation Control on a Railway Network Segment Taking into Account Random Factors. Informatics and Applications, 2017, vol. 11, no. 4, pp. 85-93. (in Russian)

3. Powell W.B., Bouzaiene-Ayari B., Lawrence C., Cheng C., Das S., Fiorillo R. Locomotive Planning at Norfolk Southern: An Optimizing Simulator Using Approximate Dynamic Programming. Interfaces, 2014, vol. 44, no. 6, pp. 567-578. DOI: 10.1287/inte.2014.0741

4. Belyy O.V., Kokurin I.M. [Organization of Rail Freight: Ways Optimization]. Transport Rossiyskoy Federatsii, 2011, no. 4, pp. 28-30. (in Russian)

5. Kibzun A.I., Naumov A.V., Ivanov S.V. [Bilevel Optimization Problem for Railway Transport Hub Planning]. Upravlenie bol'shimi sistemami, 2012, no. 38, pp. 140-160. (in Russian)

6. Lazarev A.A., Musatova E.G. The Problem of Trains Formation and Scheduling: Integer Statements. Automation and Remote Control, 2013, vol. 74, no. 12, pp. 2064-2068. DOI: $10.1134 /$ S0005117913120084

7. Lazarev A.A., Musatova E.G., Gafarov E.R., Kvaratskheliya A.G. Teoriya raspisaniy. Zadachi zheleznodorozhnogo planirovaniya [Sheduling. Problems of Rail Planning]. Moscow, Institute of Control Science of Russian Academy of Science, 2012. (in Russian)

8. Cacchiani V., Galli L., Toth P. A Tutorial on Non-Periodic Train Timetabling and Platforming Problems. EURO Transport Logistics, 2015, vol. 4, no. 3, pp. 285-320.

Received January 23, 2018

УДК $519.688+519.85+519.852 .33$

DOI: $10.14529 / \mathrm{mmp} 180107$

\section{АЛГОРИТМ ОРГАНИЗАЦИИ ЭФФЕКТИВНОЙ РАБОТЫ ПОДВИЖНОГО СОСТАВА ДЛЯ ГРУЗОВОГО ДВИЖЕНИЯ}

\author{
М.В. Буянов, А.И. Кибзун
}

Московский авиационный институт, г. Москва, Российская Федерация

Рассматривается известная математическая модель управления грузовыми перевозками. Ставится задача оптимизации управления с критерием в форме объема эксплуатируемого парка магистральных локомотивов. Предлагается альтернативная 
постановка задачи оптимизации с использованием эвристической целевой функции, позволяющая построить эффективный алгоритм решения. Описывается новый детерминированный алгоритм субоптимального управления. Указанный алгоритм является модификацией ранее предложенного, основанного на построении дерева маршрутов для каждого локомотива и, в последствии, выбора такого маршрута, при котором достигается максимальное значение заданной целевой функции. Проведены численные эксперименты на примере исторических данных Московской железной дороги. Приводится анализ и сравнение полученных результатов.

Ключевые слова: теория графов; челочисленная оптимизация; грузовые перевозки; анализ алгоритмов.

\section{Литература}

1. Azanov, V.M. Algorithm and Software Development to Allocate Locomotives for Transportation of Freight Trains / V.M. Azanov, M.V. Buyanov, D.N. Gaynanov, S.V. Ivanov // Вестник ЮУрГУ. Серия: Математическое моделирование и программирование. - 2016. - Т. 9, № 4. - С. 73-85.

2. Буянов, М.В. Развитие математической модели управления грузоперевозками на участке железнодорожной сети с учетом случайных факторов / М.В. Буянов, С.В. Иванов, А.И. Кибзун, А.В. Наумов // Информатика и ее применения. - 2017. - Т. 11, № 4. P. 85-93.

3. Powell, W.B. Locomotive Planning at Norfolk Southern: An Optimizing Simulator Using Approximate Dynamic Programming / W.B. Powell, B. Bouzaiene-Ayari, C. Lawrence, C. Cheng, S. Das, R. Fiorillo // Interfaces. - 2014. - V. 44, № 6. - P. 567-578.

4. Белый, О.В. Организация грузовых железнодорожных перевозок: пути оптимизации / О.В. Белый, И.М. Кокурин // Транспорт Российской Федерации. - 2011. - № 4. C. $28-30$.

5. Кибзун, А.И. Двухуровневая задача оптимизации деятельности железнодорожного транспортного узла / А.И. Кибзун, А.В. Наумов, С.В. Иванов // Управление большими системами. - 2012. - № 38. - С. 140-160.

6. Лазарев, А.А. Целочисленные постановки задачи формирования железнодорожных составов и расписания их движения / А.А. Лазарев, Е.Г. Мусатова // Управление большими системами. - 2012. - № 38. - С. 161-169.

7. Лазарев, А.А. Теория расписаний. Задачи железнодорожного планирования / А.А. Лазарев, Е.Г. Мусатова, Е.Р. Гафаров, А.Г. Кварацхелия. - М.: ИПУ РАН, 2012.

8. Cacchiani, V. A Tutorial on Non-Periodic Train Timetabling and Platforming Problems / V. Cacchiani, L. Galli, P. Toth // EURO Transport Logistics. - 2015. - V. 4, № 3. P. 285-320.

Михаил Владимирович Буянов, аспирант, кафедра «Теория вероятностей», Московский авиационный институт (г. Москва, Российская Федерация), buyanovmikhailv@gmail.com.

Андрей Иванович Кибзун, доктор физико-математических наук, заведующий кафедрой «Теория вероятностей», Московский авиационный институт (г. Москва, Российская Федерация), kibzun@mail.ru.

Поступила в редакцию 23 января 2018 г. 